\title{
Surface soil moisture quantification and validation based on hyperspectral data and field measurements
}

\author{
Sören-Nils Haubrock ${ }^{a}$, Sabine Chabrillat ${ }^{\mathrm{a}}$, Matthias Kuhnert ${ }^{\mathrm{b}}$, Patrick \\ Hostert $^{c}$ and Hermann Kaufmann ${ }^{a}$ \\ ${ }^{a}$ Remote Sensing Section, GFZ German Research Centre for Geosciences, Telegrafenberg, \\ 14473 Potsdam, Germany \\ soerenh@gfz-potsdam.de \\ chabri@gfz-potsdam.de \\ charly@gfz-potsdam.de \\ ${ }^{b}$ Engineering Hydrology Section, GFZ German Research Centre for Geosciences, \\ Telegrafenberg, 14473 Potsdam, Germany \\ kuhnert@gfz-potsdam.de \\ ${ }^{c}$ Geomatics Department, Humboldt-Universität zu Berlin, Unter den Linden 6, 10099 Berlin, \\ Germany \\ patrick.hostert@geo.hu-berlin.de
}

\begin{abstract}
Surface soil moisture information is needed for monitoring and modeling surface processes at various spatial scales. While many reflectance based soil moisture quantification models have been developed and validated in laboratories, only few were applied from remote sensing platforms and thoroughly validated in the field. This paper addresses the issues of a) quantifying surface soil moisture with very high resolution spectral measurements from remote sensors in a landscape with sandy substrates and low vegetation cover as well as b) comprehensively validating these results in the field. For this purpose, the recently developed Normalized Soil Moisture Index (NSMI) has been analyzed for its applicability to airborne hyperspectral remote sensing data. Three HyMap scenes from 2004 and 2005 were collected from a lignite mining area in southern Brandenburg, Germany. An NSMI model was calibrated $\left(\mathrm{R}^{2}=0.92\right)$ and surface soil moisture maps were calculated based on this model. An in-situ surface soil moisture map based on a combination of Frequency Domain Reflectometry (FDR) and gravimetric data allowed for validating each image pixel $\left(\mathrm{R}^{2}=0.82\right)$. In addition, a qualitative multitemporal comparison between two consecutive NSMI datasets from 2004 was performed and validated, showing an increase in estimated surface soil moisture corresponding with field measurements and precipitation data. The study shows that the NSMI is appropriate for modeling surface soil moisture from high spectral-resolution remote sensing data. The index leads to valid estimations of soil moisture values below field capacity in an area with sandy substrates and low vegetation cover (NDVI $<0.3$ ). Further studies will analyze the validity of the NSMI for surface soil moisture estimation from spaceborne hyperspectral sensors like the Environmental Mapping and Analysis Program (EnMap) in different landscapes.
\end{abstract}

Keywords: NSMI, soil moisture, surface moisture, HyMap, hyperspectral, field validation

\section{INTRODUCTION}

Soil moisture is one of the key variables in the hydrologic cycle controlling processes such as infiltration and discharge with consequences for surface water availability, plant growth, soil erosion and land degradation [1]. Today, it is evident that climate change has an impact not only on arid and semi-arid regions, but also on the environment of the temperate zone [2]. Predicted changes in rainfall regime as a result of global warming may affect soil moisture, surface water balance, and deteriorate ecosystem functioning [3]. Ref. 4 discovered in their 
experiments that more extreme rainfall patterns, without concurrent changes in total rainfall quantity, increase temporal variability in soil moisture and plant species diversity. Under these conditions information about soil moisture becomes increasingly important for monitoring and predicting soil erosion, land degradation and land cover changes in general.

Remote sensing offers the potential to efficiently estimate this variable at different spatial scales. Many approaches quantifying surface soil moisture from airborne or spaceborne platforms exist, but few of them are based on optical reflectance data. While in the microwave range soil moisture measurements are strongly affected by surface roughness and vegetation cover, optical remote sensing approaches have to take into account several covariates affecting reflectance values, among others soil color, soil texture, organic material and crusts [5-8]. For hydrological applications, the most important difference between optical and microwave approaches is the penetration depth and consequently the depth of the soil layer for which the water content is being quantified. Penetration depth with optical remote sensing is significantly lower, so soil moisture is quantified for the uppermost layer in a soil column. Ref. 9 analyzed the correlation of surface radiant temperature as a proxy for surface soil moisture derived from Advanced Very High Resolution Radiometer (AVHRR) data and soil moisture in deeper layers. Comparing these results, they found poor correlations and concluded that horizontal, vertical and temporal variability of soil moisture make a prediction based on top-layer remote sensing approaches very complex. However, they also found out that relationships between upper and deeper soil water content are mainly affected by soil hydraulic properties, surface variables (e.g. roughness) and spatio-temporal drying patterns, which in turn depend on initial soil moisture and potential evaporation. In the case that corresponding information is given, stronger relationships between upper and deeper soil water content are likely to exist locally, but have yet to be confirmed. In combination with data quantifying soil moisture for the upper few centimeters (like microwave or in-situ datasets), optical data could make an indispensable contribution to describe the vertical profile of soil water content and also serve as a spatial index for surface hydraulic properties of the soil.

Radiative transfer models like GeoSAIL [10] or SLC [11] are suitable means to analyze reflectance sensitivity in a theoretical framework. The influence of surface soil moisture on reflectance is considered in a submodel of GeoSAIL. Ref. 12 found out in their studies with GeoSAIL that the soil moisture effect is spectrally different from changes caused by variable plant water content and they concluded that hyperspectral sensors provide a means to distinguish between these two effects.

Many practical studies on soil moisture reflectance were performed in the artificial environment of a laboratory [13-17]. In these studies it has been confirmed that the shortwave infrared (SWIR) part of the electromagnetic spectrum is especially sensitive to soil moisture heterogeneities in different substrates. Resulting models are therefore based on the fact that increasing soil moisture up to a certain level entails a decrease in reflectance values over the visible (VIS) to SWIR range.

In most laboratory studies soil samples are prepared (i.e. cleaned, sieved and oven-dried) before being spectrally analyzed, which facilitates the derivation of successful quantification models. In contrast, results from field and remote sensing studies are more affected by natural heterogeneities and covariates. Ref. 18 addressed the challenge of providing a quantification model from heterogeneous field samples, resulting in the Normalized Soil Moisture Index (NSMI). The NSMI is based on a normalized difference of reflectance values at $1800 \mathrm{~nm}$ and $2119 \mathrm{~nm}$. It has been developed in laboratory studies measuring soil samples not modified by preparation. This approach has been determined to be the optimum quantifier of surface soil moisture in a heterogeneous field with quaternary and tertiary sands as well as clay soils in comparison with other published soil moisture quantifiers.

Besides studies based on laboratory results, approaches exist to quantify surface soil moisture from broadband optical sensors such as Landsat Thematic Mapper (Landsat ETM+), Ad- 
vanced Very High Resolution Radiometer (AVHRR), Moderate Resolution Imaging Spectroradiometer (MODIS) [9, 19-22] or simulated Satellite Pour l'Observation de la Terre (SPOT) channels [23]. Due to the relatively broad spectral resolution of these sensors, none of the models developed under laboratory conditions can be applied here without restrictions. Figure 1 shows the typical behavior of a reflectance spectrum derived from high-resolution spectral measurements of a soil sample with increasing gravimetric soil moisture (GSM). The wavelength band positions of the sensors Landsat ETM+, AVHRR or MODIS are provided for comparison, as are the wavelengths used by the NSMI.

Table 1 gives an overview of common reflectance-based soil surface moisture quantification models applied in laboratory and from spaceborne platforms.

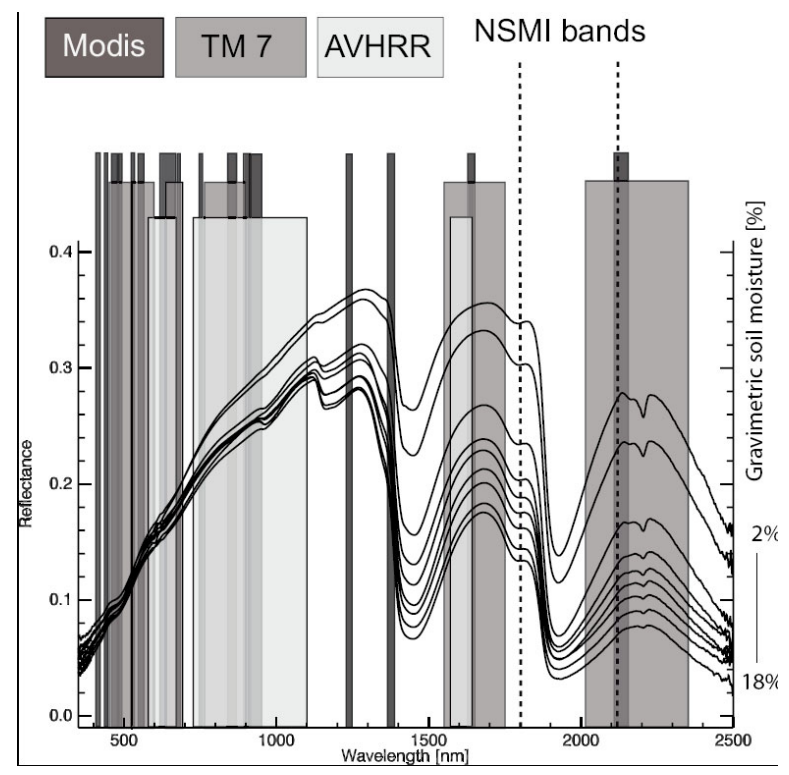

Fig. 1. Effect of increasing soil moisture on reflectance between 400 and 2500nm compared to spectral coverage and resolution of MODIS, Landsat TM-7, AVHRR sensors. The spectra are taken from an artificially wetted sample of sandy substrate. Soil moisture is measured as percentage of weight (gravimetric soil moisture).

Research on soil moisture quantification from reflectance data has shown that existing models reveal reasonable accuracies in laboratory studies but have a) rarely been validated in the field and are b) hardly ever transferable to multispectral sensors without loss. The effect of covariates and natural heterogeneity requires a more detailed investigation of valid relationships between reflectance values and surface soil moisture in the field. For this purpose, a spectrally more detailed analysis on the basis of hyperspectral imagery promises better results due to the comparability with spectral resolutions available in laboratory studies.

In this paper, we study the potential of the NSMI method for being applied to airborne remote sensing data. Multitemporal surface soil moisture quantifications based on the NSMI derived from Hyperspectral Mapper (HyMap) data are presented from a test site within the lignite mine Welzow-Süd (Germany). In contrast to Ref. 18, the analyses are focused on sandy substrates, which are mostly free of vegetation cover in the field and show more homogeneous physical and chemical properties, which is necessary for the generation of an appropriate insitu validation dataset. A new validation method is introduced based on a total of 223 field soil moisture measurements collected at overflight time, which were interpolated between point 
Table 1. Overview of common reflectance-based soil surface moisture quantification models, grouped by their application environment.

\begin{tabular}{|c|c|c|c|}
\hline Quantification model & Reference & $\begin{array}{l}\text { Wavelengths/ } \\
\text { Sensor bands }\end{array}$ & $\begin{array}{l}\text { Validation } \\
\text { method }\end{array}$ \\
\hline \multicolumn{4}{|l|}{ Laboratory studies } \\
\hline Exponential model & [14] & $350-2500 \mathrm{~nm}$ & gravimetric \\
\hline Relative reflectance & [15] & $1998 \mathrm{~nm}$ & gravimetric \\
\hline First derivative & [16] & $1834-1836 \mathrm{~nm}$ & gravimetric \\
\hline Reflectance difference & [16] & $\begin{array}{l}2250 \text { and } \\
2062 \mathrm{~nm}\end{array}$ & gravimetric \\
\hline Ratio & [24] & $\begin{array}{l}1450 \text { and } \\
1300 \mathrm{~nm}\end{array}$ & volumetric \\
\hline Moisture Determination Ratio (MDR) & [25] & $\begin{array}{l}1340,1290 \\
\text { and } 1940 \mathrm{~nm}\end{array}$ & gravimetric \\
\hline Soil Moisture Gaussian Model (SMGM) & [17] & $1200-2500 \mathrm{~nm}$ & gravimetric \\
\hline $\begin{array}{l}\text { Normalized Soil Moisture Index (NSMI) } \\
\text { (unprepared/ natural field samples) }\end{array}$ & [18] & $\begin{array}{l}1800 \text { and } \\
2119 \mathrm{~nm}\end{array}$ & gravimetric \\
\hline \multicolumn{4}{|l|}{ Remote sensing studies } \\
\hline Reflectance & [23] & SPOT & gravimetric \\
\hline Triangle method & [9] & AVHRR & $\begin{array}{l}\text { hydrological } \\
\text { model }\end{array}$ \\
\hline Broadband ratio & [19] & TM $1 / 2 / 5$ & $\begin{array}{l}\text { hydrological } \\
\text { model }\end{array}$ \\
\hline Hybrid triangle method & {$[20]$} & $\begin{array}{l}\text { ETM+ and } \\
\text { AVHRR }\end{array}$ & $\begin{array}{l}\text { climate } \\
\text { indices }\end{array}$ \\
\hline Vegetation index proxies & {$[21]$} & $\begin{array}{l}\text { MODIS } \\
\text { LAI/NDVI }\end{array}$ & $\begin{array}{l}\text { gravimetric } \\
\text { and TDR }\end{array}$ \\
\hline Angle indices & {$[22]$} & $\begin{array}{l}\text { MODIS } \\
\text { NIR/SWIR }\end{array}$ & field crop data \\
\hline
\end{tabular}

locations. With this approach we were able to assess surface soil moisture estimations based on a pixelwise comparison with concurrently measured in-situ data.

With this study, we take an important step to fill the gap between two application domains: high-precision laboratory measurements with accurate results based on synthetic surrounding conditions and broadband sensor systems with their limitations in accurately estimating and validating surface soil moisture in a natural environment.

\section{STUDY SITE}

\subsection{General Description}

A small catchment being part of a bio-monitoring reclamation zone in the lignite mine WelzowSüd near Cottbus, Germany, was selected as study site (Fig. 2). Elevations nowadays range between 129.4 and $135.6 \mathrm{~m}$ (AMSL). Slope gradients exhibit up to $25 \%$. Low mean annual rainfall and a high evaporation characterize the study site (mean for the period 1961-1990 according to Ref. 26: precipitation $563 \mathrm{mma}^{-1}$ and potential evapotranspiration 600 to $650 \mathrm{mma}^{-1}$ ). During the study period the amount of precipitation measured at a local weather station was lower than 
average (2004: $432.7 \mathrm{~mm}$; 2005: $483.9 \mathrm{~mm}$ ), while the potential evaporation was lower than average in $2004(582 \mathrm{~mm})$, but higher in $2005(735 \mathrm{~mm})$. Due to access restrictions, the area is undisturbed from anthropogenic influences. Low vegetation cover makes it suitable for remote sensing based research on soil parameters. Episodic surface runoff has formed a network of erosion rills in particular in the upper (northern-eastern) part of the test site.

\subsection{Substrates}

After the mining activities had finished in 2001, different substrates were dumped at the test site. An aquiclude (clay layer) is located at a depth of about two meters below the surface. The dumped substrates form a shallow aquifer above the clay layer, with groundwater levels located about $0.5 \mathrm{~m}$ to $1.5 \mathrm{~m}$ below the terrain surface. The dumped substrates are quaternary and tertiary sands, which are coarsely textured and contain less than $4 \%$ clay. Both substrates were mapped as Technosol according to the World Reference Base (WRB) classification in Ref. 27.

The tertiary substrate in the northern part of the test site is characterized by very coarse grain sizes $(44.7 \%>630 \mu \mathrm{m})$ resulting in a poor water storage capability (field capacity) [28]. Surface soil moisture values are therefore highly dynamic in time. The area is nearly free of any vegetation cover due to the high soil acidity ( $\mathrm{pH}$-value about 3.1 ). This part of the test site has the highest elevation with a slope facing southward.

In the adjacent area quaternary sand is predominating. A slightly acid character ( $\mathrm{pH}$-value about 5.6) and low to moderate field capacity is characteristic for this substrate [28]. Surface processes have formed a more differentiated spatial substrate distribution after 2001 (see Fig. 2). Soil erosion patterns show a discharge of material from the upper part (tertiary substrate) and an accumulation of substrates with smaller grain sizes and very distinct chemical properties further south. Especially in the northern part of the quaternary sands, eroded substrates have accumulated and developed a specific formation that can be clearly distinguished from the surrounding substrates by their color, constituents and vegetation cover. Typical for this accumulation area is its high content in $\mathrm{Fe}_{2} \mathrm{O}_{3}$, which originates from chemical processes typical for lignite mines (compare [29]). As a consequence, vegetation is absent here. In contrast, the surrounding areas show a relatively high vegetation cover. A naturally developed discharge and erosion channel further west transports water and sediments in a southerly direction and exhibits specific mineral crusts on top of the mainly quaternary substrates.

\subsection{Data}

\subsubsection{Datasets for NSMI model setup}

In the scope of this study, three HyMap scenes covering the test site were recorded during the HyEurope 2004 and 2005 campaigns organized by the German Aerospace Center. HyMap measures radiance in 126 bands covering the 440 to $2470 \mathrm{~nm}$ wavelength region with a spectral resolution between 13 and $17 \mathrm{~nm}$ [30]. Calculating reflectances from original radiance values was necessary to comply with field and laboratory based measurements. All scenes (Table 2) cover the entire test site under cloud-free conditions. The images were acquired with $4 \mathrm{~m}$ ground resolution and a swath width of $2048 \mathrm{~m}$.

Calibration of the NSMI regression function for HyMap application was performed with independent long-term datasets. Seven sampling campaigns were undertaken between 2004 and 2005 collecting $5 \mathrm{~cm}$ deep soil cores from nine different locations in the field covering all substrates under survey. Within 24 hours the sealed samples were brought to the laboratory and subdivided into five layers (sub-samples) of $1 \mathrm{~cm}$ width with the aid of a trowel. 208 reflectance spectra were measured using an Analytical Spectral Devices (ASD) FieldSpecPro FR(C)spectroradiometer, covering the 350-2500nm spectral region with 2151 bands resampled to $1 \mathrm{~nm}$. Gravimetric soil moisture values were determined for each layer applying conventional oven-drying for 24 hours at $105^{\circ} \mathrm{C}$. These values range between 0 and $25 \%$ and as such 

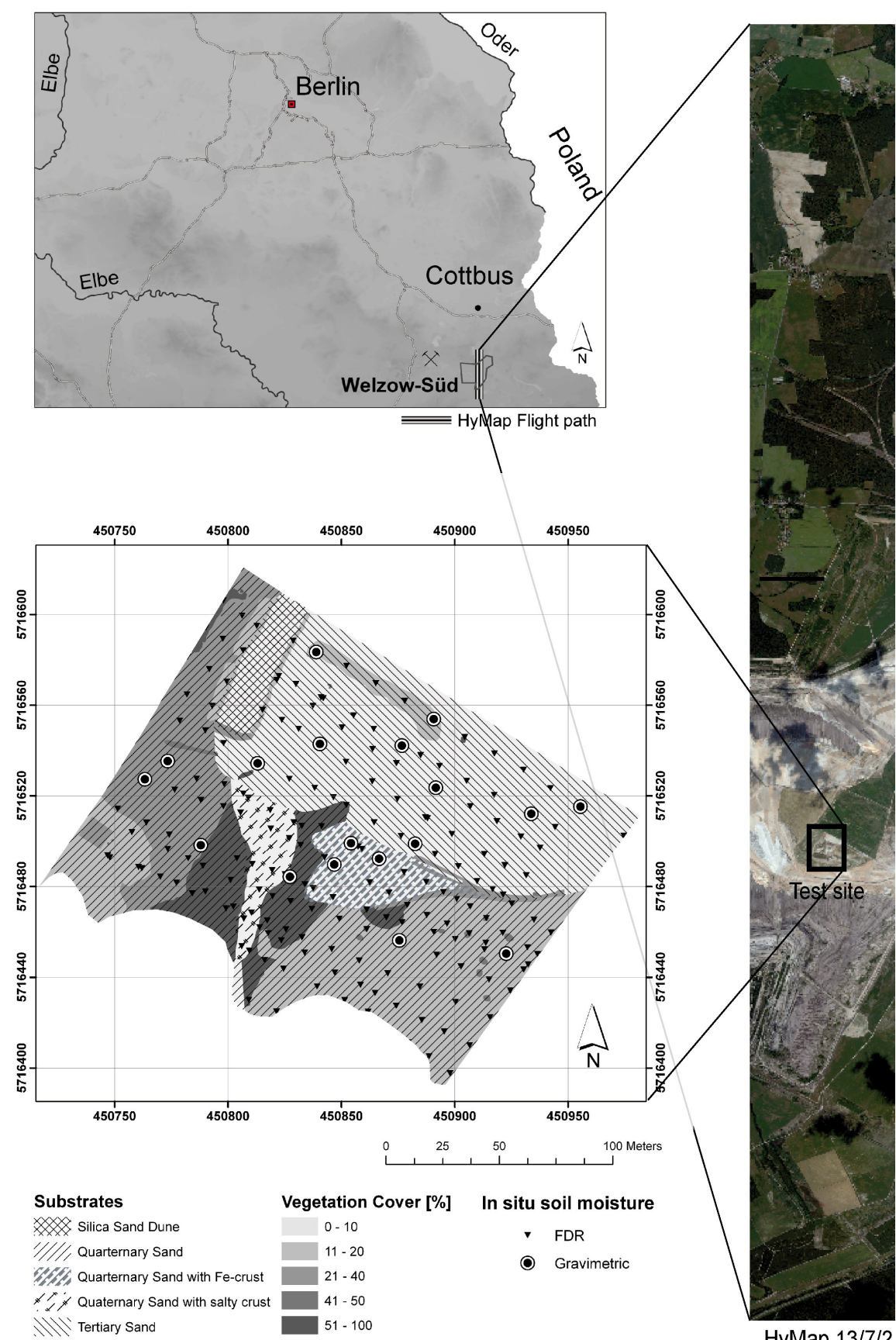

HyMap 13/7/2

Fig. 2. Test site with soil types and vegetation cover (as from June 2005). Vegetation cover has been estimated in the field and by digital photography. (Spatial reference system: Universal Transverse Mercator (UTM 33N), World Geodetic System (WGS 1984)) 
Table 2. HyMap scene characteristics.

\begin{tabular}{|c|c|c|c|c|c|c|}
\hline \multirow{2}{*}{$\begin{array}{l}\text { Scene } \\
\text { No. }\end{array}$} & \multirow{2}{*}{$\begin{array}{l}\text { Acquisition } \\
\text { date }\end{array}$} & \multirow{2}{*}{$\begin{array}{l}\text { Acquisition } \\
\text { time } \\
\text { [CEST] }\end{array}$} & \multirow{2}{*}{$\begin{array}{l}\text { Average } \\
\text { flight } \\
\text { height } \\
\text { [m] }\end{array}$} & \multirow{2}{*}{$\begin{array}{l}\text { Average } \\
\text { flight } \\
\text { direction } \\
\left.{ }^{\circ}\right]\end{array}$} & \multicolumn{2}{|c|}{ Illumination } \\
\hline & & & & & $\begin{array}{l}\text { Sun } \\
\text { zenith } \\
{\left[{ }^{\circ}\right]}\end{array}$ & $\begin{array}{l}\text { Sun } \\
\text { azimuth } \\
{\left[{ }^{\circ}\right]}\end{array}$ \\
\hline 1 & 2004, July 7th & 11:58am & 2006 & -2.2 & 31.92 & 149.38 \\
\hline 2 & 2004, July 30th & $10: 34 \mathrm{am}$ & 1997 & 0.47 & 45.09 & 122.87 \\
\hline 3 & 2005, June 20th & 1:50pm & 2077 & 0.0 & 29.24 & 199.39 \\
\hline
\end{tabular}

cover the whole domain of soil moisture values for which the NSMI had been developed in the laboratory [18].

For image pre-processing purposes, 377 reference spectra were taken in the field simultaneous with image recording in 2005. Additional spectra were taken from characteristic surfaces outside the test site to improve the radiometric correction of the image (e.g. dark asphalt from a parking lot). All spectra were acquired with nadir view from approximately $1 \mathrm{~m}$ height, resulting in a field of view (FOV) of $\sim 40 \mathrm{~cm}$ in diameter. To cover larger areas and for enhancing the signal-to-noise-ratio (SNR), spectra were taken while walking with the ASD device. For each of the 5 to $10 \mathrm{~m}$ long transects, 100 spectral measurements were averaged. The area of interest was completely covered by walking in parallel lines. Differential Global Positioning System (DGPS) data were collected to locate the transects.

In order to measure a distinct contrast in soil moisture within a single substrate an area of approximately $100 \mathrm{~m}^{2}$ was artificially wetted shortly before the overflight in 2005 with 200 liters of water.

\subsubsection{In-situ soil moisture data}

Volumetric soil moisture values were measured in the field using Frequency Domain Reflectometry (FDR) devices on 2005, June 20th. FDR devices can be used for estimating the volumetric soil moisture values for the upper five $\mathrm{cm}$ column based on soil electric properties [31,32].

205 FDR values were collected within three hours around overflight time. Measurements were acquired every $\sim 5 \mathrm{~m}$ on transects that were $10 \mathrm{~m}$ apart resulting in a mesh of point measurements of $5 \times 10 \mathrm{~m}$ ground resolution, which was interpolated to a $4 \times 4 \mathrm{~m}$ raster image to facilitate comparisons with the HyMap scene. For geocoding the in-situ data, DGPS values were recorded for each FDR measurement.

For a more accurate quantification of the uppermost surface soil moisture, 18 soil core samples were additionally collected in the field at overflight time. Sampling locations were chosen randomly while covering all substrates differentiated in the field. Gravimetric soil moisture values and reflectance spectra were determined following the same procedure as described previously. Soil moisture values for the layer of $0-1 \mathrm{~cm}$ depth were determined separately, allowing for a direct comparison between parameters based on reflectance values and in-situ data. Furthermore, the information on soil moisture variation within the vertical profile of the upper $5 \mathrm{~cm}$ was used to calibrate the FDR measurements in the field for validation purposes. In addition to the measurements undertaken simultaneously with image acquisitions, long-term soil moisture data series were collected with an echo probe device to gain an insight into the temporal behavior of soil moisture for qualitatively validating the NSMI results for the 2004 HyMap scenes. 


\section{METHODOLOGY}

For the purpose of surface soil moisture quantification and validation at the micro-catchment scale a comprehensive methodological concept has been developed. Figure 3 shows the components of this approach, which are described in more detail in the following.

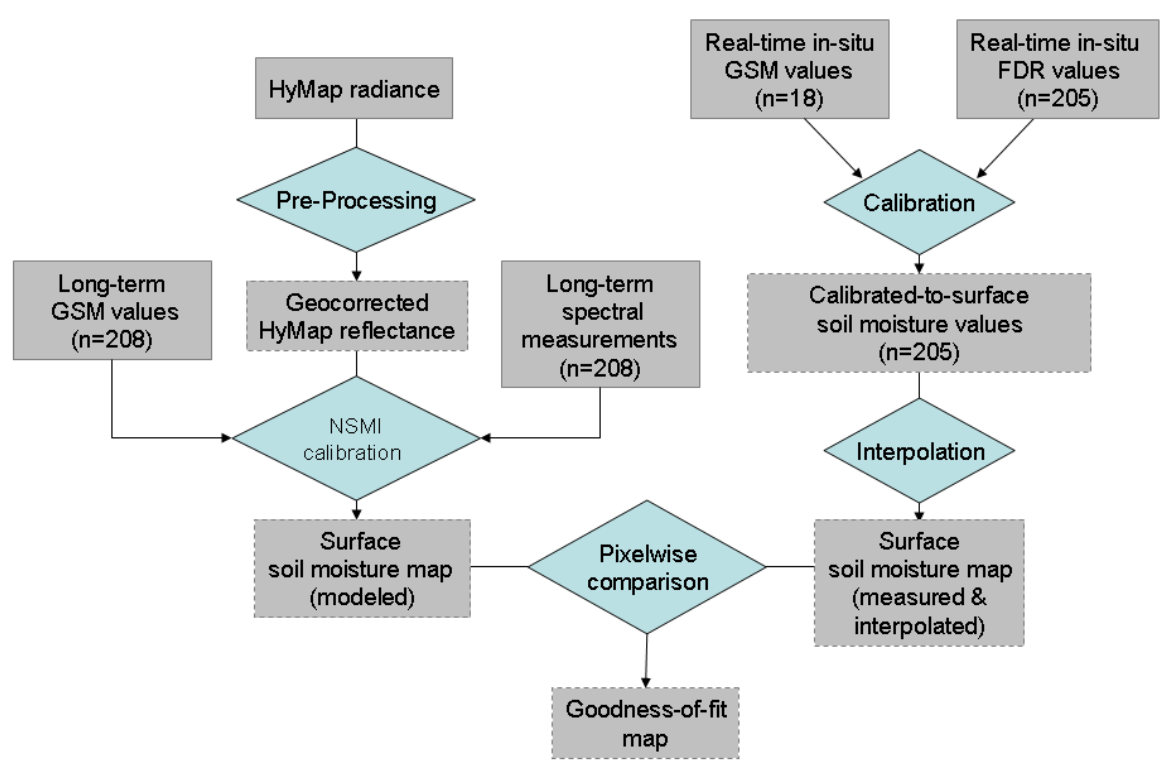

Fig. 3. Methodological concept for surface soil moisture estimation and validation.

Applying and evaluating a model on surface soil moisture quantification at the field scale involves two sequences of processing and analysis steps: a) quantifying soil moisture based on reflectance data and b) generating a validation map based on in-situ and laboratory measurements. The data sets collected in the scope of the HyMap 2005 campaign were used for setting up the quantification model and validation maps. The resulting model was then applied to the other two images and compared to meteorological and in-situ soil moisture data.

\subsection{Pre-processing of HyMap images}

The HyMap scenes were atmospherically corrected using an in-house developed hybrid method (ACUM algorithm). It employs MODTRAN 4 [33] to calculate at-surface reflectance. The algorithm includes a scan angle dependent correction accounting for the large field of view of $61.3^{\circ}$ and an adjacency effect correction. The resulting spectra were adjusted via empirical line calibration based on field spectra to minimize the residual artifacts around major water absorption bands. The field spectra were acquired at overflight time over homogeneous bare surfaces (bright soils, dark soils, asphalt). They were resampled to the spectral resolution of the HyMap sensor and geometrically mapped based on DGPS measurements before performing the empirical line calibration.

Parametric georectification removed scanline artifacts caused by aircraft movements. It was based on the DGPS coordinates measured for each scanline position on board of the aircraft 
in addition to the sensor calibration information and the flight parameters pitch, roll and heading. Additional reference points $(n=12)$ from digital topographic maps $(1: 50,000)$ were used to account for remaining pixel shifts and to reconstruct the exact scanline of the aircraft, finally resulting in a root mean square error (RMSE) of $1.66 \mathrm{~m}$.
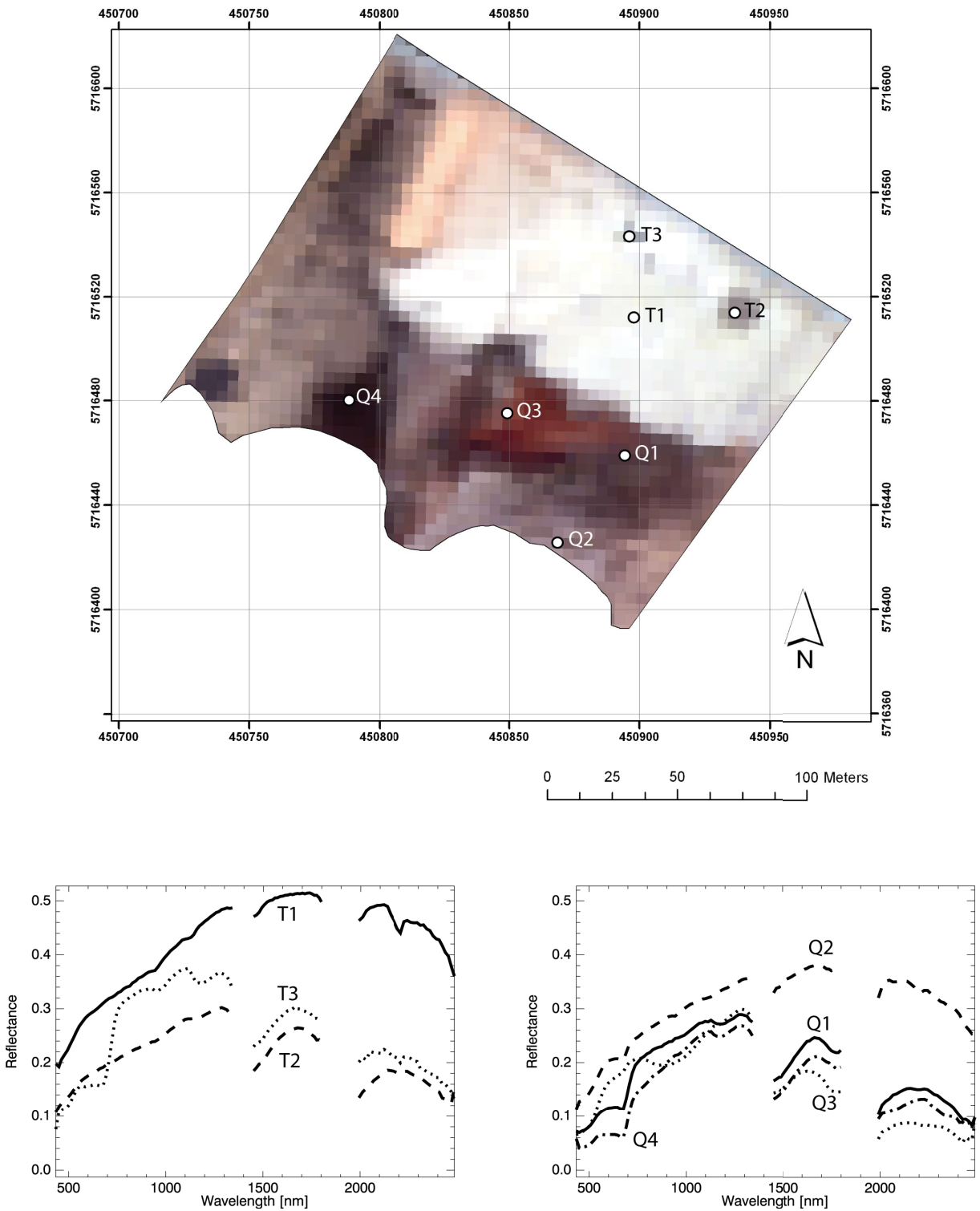

Fig. 4. True-color image in grey-coded scale of the pre-processed HyMap scene 2005 from the test site with representative image spectra from the tertiary (T1-T3) and quaternary (Q1-Q4) areas.

After atmospheric modeling and empirical line calibration, the resulting image spectra consisting of 126 wavelength channels showed good accordance with independent field spectra resampled to HyMap spectral resolution. The highest discrepancies in reflectance (up to 0.04) 
occur for soil spectra near the water absorption bands at 1400 and 1900nm. For the NSMI approach followed here, where reflectance values near 1800 and $2119 \mathrm{~nm}$ are considered, residual errors after calibration are within $2 \%$.

Figure 4 shows the resulting HyMap image of the test site (color composite with red-greenblue (RGB) channels at HyMap bands 13-7-2, centered around 615nm-523nm-449nm) with representative image spectra taken at characteristic locations. Spectra T1 to T3 are taken from samples in the tertiary substrate. Most pixels in this area show soil reflectance characteristics similar to T1, with a typically high albedo and distinct absorption features in the SWIR diagnostic of clay fractions. Due to the absence of vegetation here, a red edge is not present. In contrast, T3 shows a spectrum associated with the only significantly vegetated part in the tertiary sand, where an area of around $3 \times 3 \mathrm{~m}$ is covered with reed. An important effect of soil moisture on the spectrum of a HyMap pixel can be seen in spectrum T2. It has been collected from the $10 \times 10 \mathrm{~m}$ area that had been artificially wetted just before image acquisition time. The substrate in this area is equivalent to the one resulting in spectrum T1, but the higher soil moisture value severely affects the shape of its spectrum. It can be seen that not only the overall albedo is lower than in T1, but also the absorption band around $1900 \mathrm{~nm}$ is more pronounced and the clay diagnostic feature at $2200 \mathrm{~nm}$ has been drastically reduced. The difference in reflectance between the bands below and above the 1900nm absorption band is higher. This well-known effect of increasing soil moisture is crucial for the NSMI quantification approach applied in this study. The pixels from the quaternary substrate are characterized by darker, grey-brownish color in the RGB image. Different subtypes within the quaternary soil can be reconstructed in this image. Increasingly reddish color tones can be observed in the regions of large iron content associated with diagnostic iron features in Q3. Additionally, higher density in vegetation can be identified by dark pixel values in the image.

The image spectra reflect the natural heterogeneity of the surface substrates in the area studied. Figure 4 shows that soil moisture estimations based on the overall albedo decrease are of limited use here since they are partly caused by variable soil physical and chemical composition of substrates in the field.

\subsection{Soil moisture estimates from reflectance data}

To provide a model for surface soil moisture quantification based on reflectance data measured with the HyMap sensor, a calibration based on laboratory measurements was performed.

The NSMI was used to estimate surface soil moisture from HyMap data according to the normalized difference equation 1.

$$
\begin{aligned}
\text { NSMI } & =\frac{\sigma[1800 \mathrm{~nm}]-\sigma[2119 \mathrm{~nm}]}{\sigma[1800 \mathrm{~nm}]+\sigma[2119 \mathrm{~nm}]} \\
\sigma & : \text { reflectance. }
\end{aligned}
$$

The NSMI represents a dimensionless parameter that can be used to quantify gravimetric soil moisture using the linear relationship

$$
\begin{aligned}
G S M= & a+b * N S M I \\
G S M: & \text { gravimetric soil moisture }[\mathrm{g} / \mathrm{g}], \\
a, b: & \text { offset and gain in linear regression } \\
& \text { function. }
\end{aligned}
$$


Table 3. Bands / center wavelengths chosen for application of NSMI with HyMap data.

\begin{tabular}{lllll}
\hline Date & $\begin{array}{l}\text { Wavelength 1 } \\
{[\mathrm{nm}]}\end{array}$ & $\begin{array}{l}\text { FWHM } \\
{[\mathrm{nm}]}\end{array}$ & $\begin{array}{l}\text { Wavelength 2 } \\
{[\mathrm{nm}]}\end{array}$ & $\begin{array}{l}\text { FWHM } \\
{[\mathrm{nm}]}\end{array}$ \\
\hline $\begin{array}{l}\text { 2004, July 7th and } \\
\text { 2004, July 30th }\end{array}$ & 1793.1 & 13.1 & 2116.5 & 20.1 \\
2005, June 20th & 1798 & 12.9 & 2120 & 20.2 \\
\hline
\end{tabular}

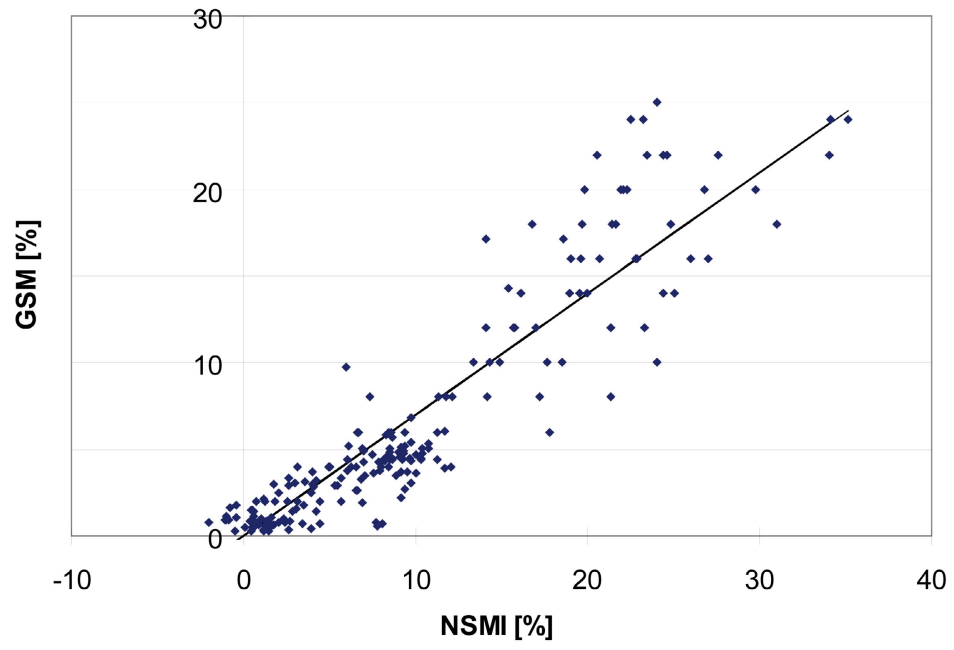

Fig. 5. Calibration function based on a long-term measurement series of gravimetric surface soil moisture and NSMI values generated from ASD spectra resampled to HyMap spectral resolution. Linear regression parameters: $a=0, b=0.7 ; R^{2}=0.92 ; R M S E=2.55 \%$ GSM $(n=208)$.

The full width at half maximum (FWHM) spectral resolution between 6 and 21nm required an adaptation of the NSMI for the HyMap sensor. Slight shifts in the index occurred in the datasets due to different band center wavelengths in the sensor calibrations for the three datasets (Table 3).

The 208 long-term ASD spectra described in 2.3.1 were resampled to HyMap spectral resolution. The bivariate dataset was used for a least-square linear regression analysis between HyMap-resampled NSMI and GSM. Gain and offset values according to equation 2 were determined (Fig. 5) and applied to all images.

\subsection{Determination of surface soil moisture from in-situ data}

The 205 FDR samples measuring average soil moisture values of the upper five centimeters allow for an appropriate spatial coverage to generate validation points for each pixel of the HyMap images. Since soil moisture in the upper five centimeters is in most cases not identical with the soil moisture at the surface, the FDR values needed to be calibrated-to-surface to allow a comparison with optical remote sensing data. The additionally collected soil cores provided information on the vertical soil moisture distribution via separate measurements within five layers (one layer per $\mathrm{cm}$ ). Soil specific vertical soil moisture distribution information could be gained from these datasets for each substrate. Preliminary analyses showed that soil moisture profiles were relatively homogeneous within each substrate in the field, so a relatively small number of samples was considered sufficient for representing substrate typical proxies for a total of 18 cores. 


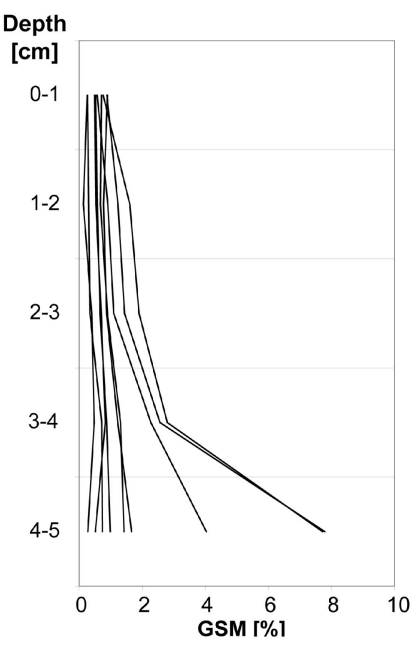

a)

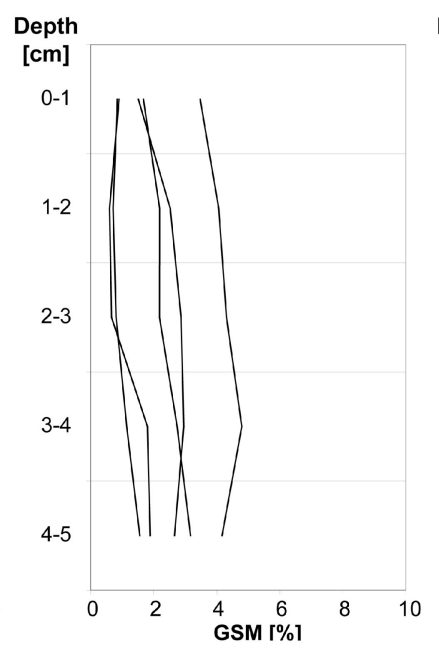

b)

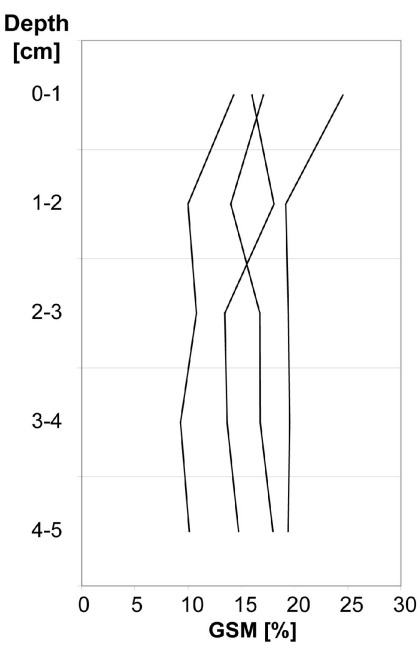

c)

Fig. 6. Vertical soil moisture distribution from 18 soil cores on 2005/06/20: a) tertiary sand, b) quaternary sand, c) impure quaternary sand (affected by $\mathrm{Fe}_{2} \mathrm{O}_{3}$, crusts, lichens etc.).

A graphical representation of the vertical soil moisture distribution measured in the field is given in Fig. 6. The vertical distribution shows typical patterns for each of the substrates. In the case of the tertiary sand, the tendency of increasing soil moisture with increasing depth would lead to an overestimation of surface soil moisture when averaging over the upper five centimeters.

Linear relationships between volumetric soil moisture values based on $5 \mathrm{~cm}$ average FDR measurements and gravimetric soil moisture values of the uppermost layer based on core samples were established and applied as correction factors to account for the deviation between five-centimeter mean and top layer values. Specific values were calculated for the tertiary and quaternary substrate as well as for those quaternary samples that were affected by crust formation or significant $\mathrm{Fe}_{2} \mathrm{O}_{3}$ amounts. Conversion to gravimetric soil moisture was based on the average bulk density of $1.68 \mathrm{gcm}^{-3}$.

The resulting calibration-to-surface factors for the three soil classes have been applied as follows:

$$
\begin{aligned}
G S M & =\alpha * V S M / B D \\
G S M & =\text { gravimetric soil moisture }[\mathrm{g} / \mathrm{g}], \\
\alpha & = \begin{cases}0.59, \text { for tertiary substrates, } \\
0.76, \text { for quaternary substrates, } \\
1.21, \text { for affected quaternary substrates, }\end{cases} \\
B D & =\text { bulk density, here } 1.68\left[\mathrm{~g} / \mathrm{cm}^{3}\right], \\
V S M & =\text { volumetric soil moisture from FDR measurements }\left[\mathrm{cm}^{3} / \mathrm{cm}^{3}\right] .
\end{aligned}
$$

FDR values were adapted based on these calibration factors resulting in RMSE values of $1.94 \%$ GSM for the difference between FDR and gravimetric measurements. 
Finally, a mesh of surface soil moisture data points was generated at the spatial resolution and coverage of the FDR measurements. For each of the substrates differentiated in the field (Fig. 2), the calibrated-to-surface FDR measurements were interpolated between all points using an Inverse Distance Weighting (IDW) algorithm (inverse quadratic distance to three reference points) [34]. A separate interpolation for each soil type was necessary due to very sharp variations of surface soil moisture with substrate changes. The resulting raster maps were combined for all soil types and resulted in a $4 \mathrm{~m}$ resolution surface soil moisture validation dataset.

The accuracy of the interpolated pixel values was validated against a subset of 20 FDR point measurements based on regular sampling. For validation purposes, these measurements were not considered in the interpolation, but compared to interpolated values applying a leave-oneout strategy. Validation led to an RMSE of $2.07 \%$ GSM (median $0.38 \%$, max 5.2\%), which is below common uncertainties caused by the measuring device. The resulting uncertainty for the final in-situ dataset is therefore in an acceptable range for validation purposes in this study. Interpolation was particularly successful in the tertiary sand, where more homogeneous soil moisture distributions were observed. More critical was the part in the quaternary substrate with high spatial heterogeneities. Here, an increase in the number of FDR measurements certainly would have improved the interpolation results with deviations of up to $5.2 \%$. The resulting dataset is nevertheless invaluable for a pixelwise comparison with remote sensing data, although the given restrictions need to be taken into account for interpretation.

\subsection{Validation of soil moisture model}

A difference map was calculated between in-situ surface soil moisture estimates and HyMapbased NSMI for the scene from June 2005. Specific spatial patterns of conformance and deviation were discussed and the influence of vegetation cover and mixed substrates was further analyzed. To verify that the chosen HyMap channels (see Table 3) provide optimum results for soil moisture quantification in this analysis, local variations in the choice of bands for NSMI calculation were evaluated.

The NSMI model was finally applied to the HyMap scenes from 2004. The two resulting maps quantifying surface soil moisture for the beginning and end of July 2004 were compared to each other by generating a moisture difference map. Precipitation data and soil moisture values from a time series over two months were qualitatively compared to the variation in the NSMI-based soil moisture estimation.

\section{RESULTS AND DISCUSSION}

The goal of this paper is to analyze the potential of the NSMI index resampled to hyperspectral sensor resolutions for quantifying surface soil moisture. For this purpose the outcome of the quantification model is described and compared to the in-situ dataset derived from FDR and gravimetric samples in the field by calibration and interpolation. In the following, each resulting dataset is shortly described according to its spatial distribution pattern, before they are compared to each other by difference maps and statistical measures. The applied methods are discussed with respect to their success and limitations.

\subsection{Estimation of surface soil moisture from reflectance data}

Resulting gravimetric soil moisture estimations are in the range of 0 to $18.9 \%$ with a mean of $3.8 \%$, and standard deviation of $5.2 \%$ (Fig. 7 a). The overall surface soil moisture pattern deduced from the NSMI model can be depicted as follows: the tertiary sand shows mainly spatially homogeneous values below $4 \%$. Two small areas stand out against this homogeneous pattern. An area of two adjacent pixels in the center of the tertiary substrate show higher values than the surrounding parts. Reeds covering a few square meters affect the reflectance values in the HyMap image and lead to an overestimation by the NSMI model. The second outstanding 


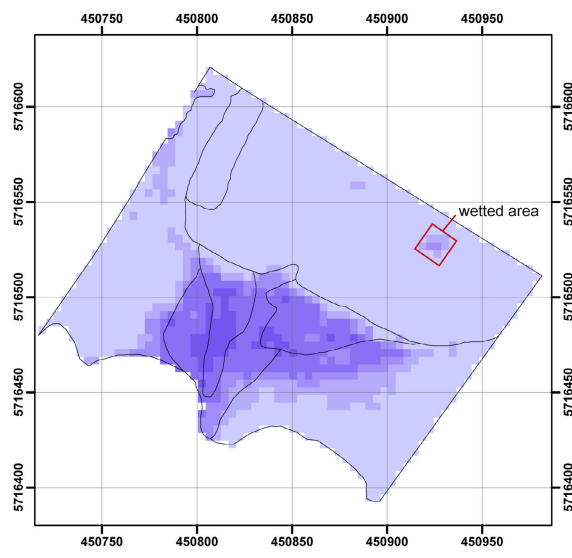

a) HyMap-derived NSMI

$0 \quad 45 \quad 90$

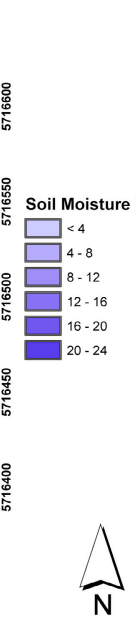

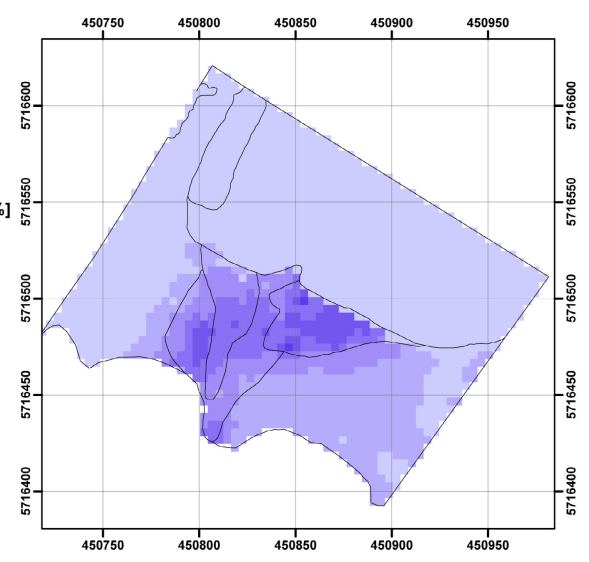

b) In-situ estimation

$\square$ Substrate boundaries

Fig. 7. a) Surface soil moisture derived from HyMap applying the NSMI. b) Surface soil moisture map derived from in-situ measurements on 2005/06/20.

soil moisture pattern further east is caused by the artificial wetting of an area of $10 x 10 \mathrm{~m}^{2}$ shortly before the time of the HyMap overflight. Values range here between 8 and $18 \%$ at the surface, which reasonably reflects the resulting moisture caused by wetting and subsequent infiltration.

The values estimated for the quaternary substrates in the southern part of the image show a much more heterogeneous structure. In the center where elevation is lowest and erosion processes have formed a discharge channel, soil moisture is estimated highest with values around $18 \%$. With increasing spatial distance from this accumulation zone, the values drop towards 0 in easterly and westerly directions. An elongated area of a few square meters in the north-western part of the quaternary substrate shows relatively high estimated surface soil water content between 4 and $8 \%$. The sand dune area and the adjacent parts of the tertiary sand east of it represent the driest region in the map, with 0 to slightly negative GSM predictions. The latter are caused by the fact that reflectance at $2119 \mathrm{~nm}$ is equal to or slightly higher than reflectance at $1800 \mathrm{~nm}$ in these pixels. The sand dune with its different color and physico-chemical properties not taken into account in the NSMI model calibration is therefore subject to underestimations of up to $2 \%$ GSM. The mainly westerly wind direction additionally led to a deposition of dune sands on top of the tertiary sands, affecting the NSMI quantification also for the area adjacent to the dune. NSMI estimations are in average $1 \%$ lower here than in the pure tertiary substrate.

\subsection{Determination of surface soil moisture from in-situ data}

FDR measurement values in the field range between 0.7 and $35.1 \%$ volumetric soil moisture, which corresponds to 0.4 to $20.7 \%$ gravimetric soil moisture applying the calibrationto-surface procedure. This range corresponds with long-term gravimetric measurement values (max. 25.7\% GSM). However, the RMSE value for the calibration-to-surface of 1.94\% GSM would have been higher if no strong relationships between soil moisture in the different layers were present. As discussed in Ref. 9, stable relationships can be found either in the first phase of a typical drying scenario, i.e. directly after precipitation events and before a significant drying process has started, as well as in the third phase after drying processes in the upper centimeters of the soil column have finished, finally resulting in homogeneously dry compartments. On June 20th 2005, the drying process was in this third phase after five days without precipitation.

The subsequent interpolation procedure of the calibrated-to-surface FDR values led to a HyMap resolution pixel-by-pixel map, which is shown in Fig. 7 b. The range of values derived 
from the spatial interpolation of calibrated FDR measurements (0.3 to $20.5 \%$, mean: $4.2 \%)$ corresponds with the calibrated-to-surface FDR point measurements.

Figure 8 shows the effect of the two-step correction of in-situ data by calibrating to surface values and interpolation. Both steps increase the linear correlations between field data and NSMI estimated. While the improvement caused by surface calibration accounts for the vertical differences in an appropriate way, the interpolation obviously reduces the effect of local inconsistencies within an area of one pixel $(4 \times 4 \mathrm{~m})$. FDR point measurements can vary within centimeters and exact sampling locations can thus be critical. The smoothing effect of the interpolation is therefore beneficial for a pixelwise comparison of the two datasets.

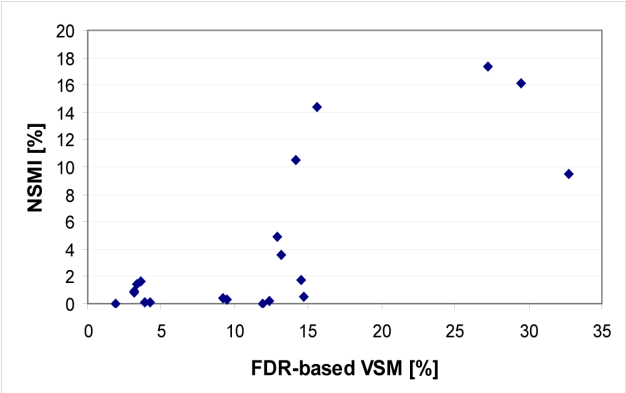

$\mathrm{R}^{2}=0.60$

a)

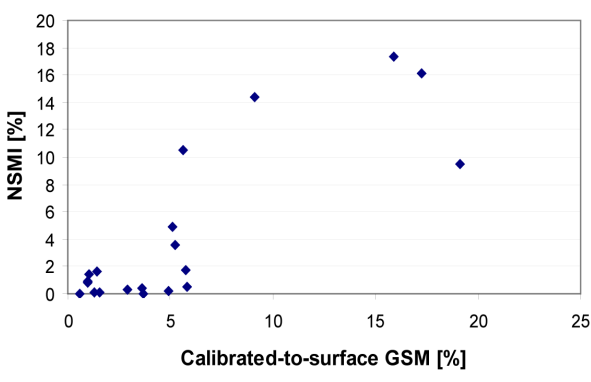

$R^{2}=0.69$

RMSE $=3.2$

b)

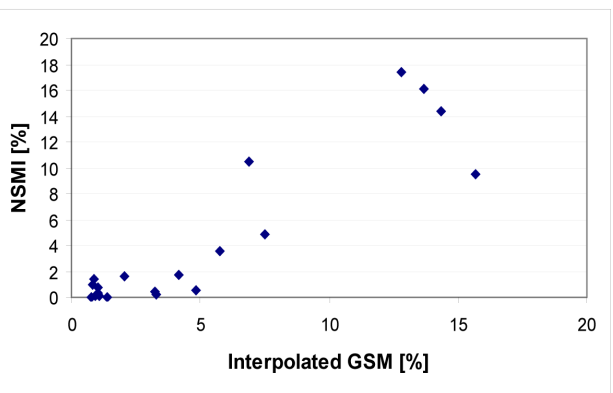

$\mathrm{R}^{2}=0.82$

$\mathrm{RMSE}=2.46$

c)

Fig. 8. Correlations between NSMI values and intermediate results of validation dataset based on a validation subsample ( $\mathrm{n}=20$, regular sampling): a) FDR values of upper $5 \mathrm{~cm}$ soil column, b) calibrated-to-surface GSM values and c) interpolated GSM values from the field.

The general pattern of soil moisture distribution is well reflected by the data. For the tertiary sand, a nearly homogeneous area of low surface soil moisture $(<4 \%)$ is obvious in the in-situ map. It can be observed that, due to the early acquisition of FDR measurements before the wetting process, the 10x10m wetted area is not visible in this FDR-based dataset. Also the reed area does not show higher soil moisture values than the surrounding area. In the quaternary 
substrate, the eastern part (east of the accumulation zone) shows relatively homogeneous values in the range of $4-8 \%$, while the western part is similarly homogeneous, but slightly dryer $(<4 \%)$. Due to the interpolation method applied here, the sharp transition of values between substrate boundaries could be reproduced, while more quasi-continuous gradients are present within a substrate.

\subsection{Validation of the soil moisture model}

A good conformance between remote sensing prediction and corresponding field interpolation GSM values has been shown in Fig. 7. In order to analyze the differences between the two datasets in more detail, a deviation map was generated (Fig. 9). Several patterns can be identified, giving indications of the locations and consequently of the circumstances under which the soil moisture estimations show corresponding or differing results. In the following all values are given as absolute GSM percentages.

Differences of the approaches amounted to $-0.30 \%$ in average with an RMSE of $2.3 \%$. In the tertiary substrate, higher soil moisture values based on reflectance data within the artificially wetted area can be explained since they are correctly detected by the NSMI model, but not included in the interpolation of FDR measurements. The correct estimation of the NSMI approach has been approved here by analyzing four soil core measurements conducted within the artificially wetted area, resulting in an averaged field value of $\sim 12 \%$, which corresponds with the NSMI values for this location. The second area showing differences between the two datasets is in the upper middle of the tertiary sand. The Normalized Difference Vegetation Index (NDVI) value (Fig. 9b) reflects the density of the reed scrub, leading to an overestimation of surface soil moisture in two pixels. Apart from these two spots where NSMI-deduced quantities are higher than field-based quantities, also a slightly increasing deviation can be observed from the middle of the tertiary area towards the sand dune in the north-west of the test site. NSMIbased values are marginally smaller than field-based measurements here. This underestimation of the NSMI is caused by the presence of the dune substrate introducing a minor inaccuracy in the soil moisture prediction as discussed earlier. The NSMI model therefore appears to be adequate for quantifying surface soil moisture in the case of the tertiary sand under the premises that vegetation cover is sparse and no additional substrates are present in significant amounts.

In the quaternary substrate, the deviation map shows more pronounced spatial heterogeneities. The highest deviation is located at the border between tertiary and quaternary substrates and is caused by two different factors. Firstly, the raster cells generated from the HyMap image represent mixed pixel values along the borderline, while the in-situ map shows a very sharp gradient caused by the substrate-specific interpolation. As a consequence, some pixels directly south of the borderline represent mixed values averaged over both substrates in the NSMI map and therefore show inconsistencies with the interpolated in-situ dataset. Secondly, the specifically high soil moisture values measured by the FDR device are not reproduced by the NSMI model. It has been noted in the field that surface soil moisture was partly above field capacity here, i.e. the surface was covered with water, which additionally contained iron compounds and other chemical constituents affecting its color. Surface soil moisture above field capacity is inaccurately reproduced by the NSMI model as expected.

Considering the NDVI map in Fig. 9b, an additional effect to note is the influence of the vegetation cover on the deviation map. Similar to the case in the tertiary sand, a high NDVI value corresponds with an overestimation of the NSMI value in the quaternary substrate. Vegetation water content is likely to affect the NSMI model outcome here, since a change in vegetation water content has a similar effect on reflectance in the SWIR part of the spectrum. In the parts of the accumulation delta where vegetation is relatively low or absent, estimations by the NSMI model are consistently smaller compared to the field-based quantification. Since surface soil moisture values are particularly high at this location (partly above field capacity), a lower accuracy of the NSMI model is observed. Another factor affecting the remote sensing estimate is 


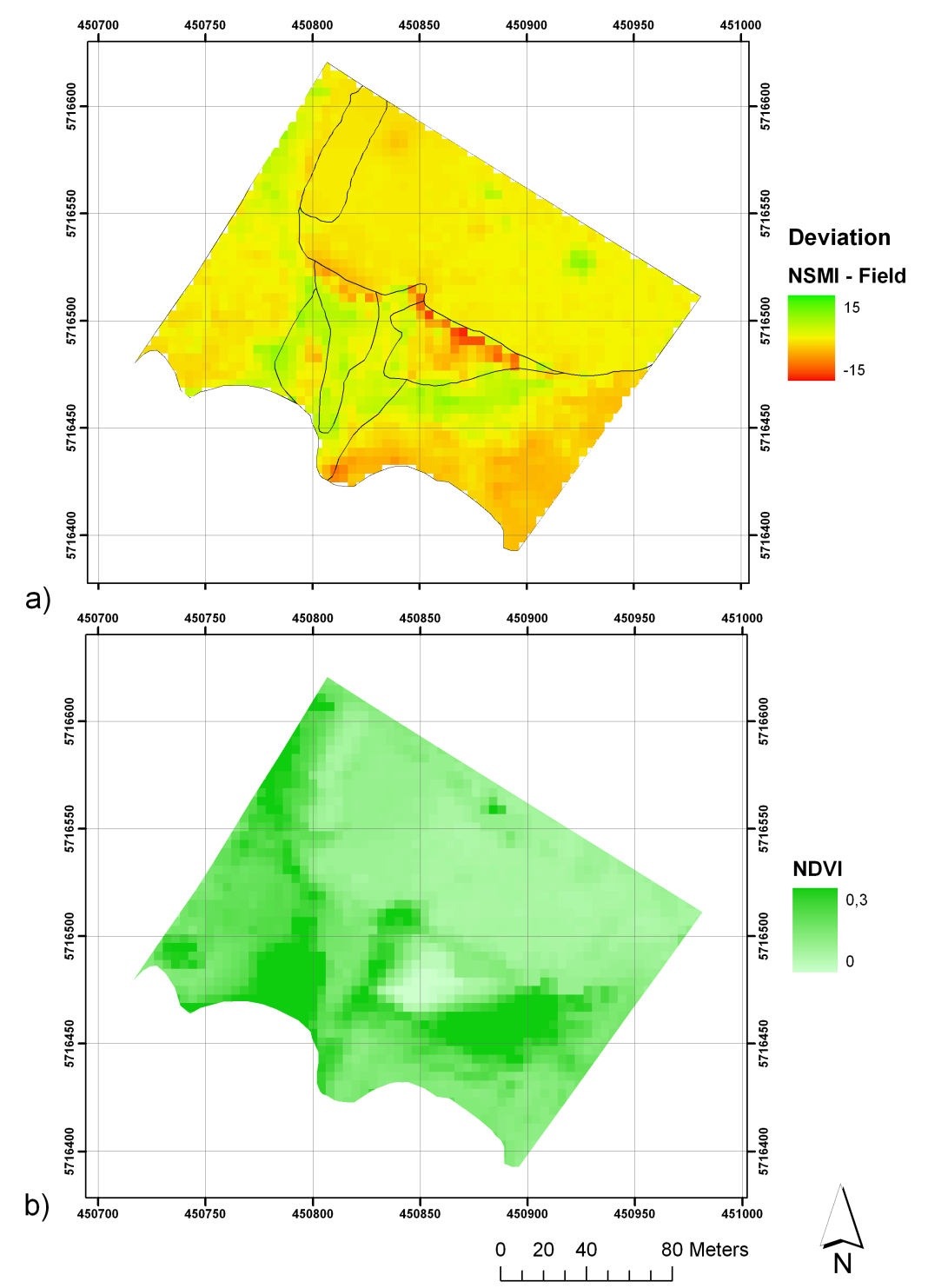

Fig. 9. a) Map of deviation between HyMap-derived surface soil moisture and calibrated FDRbased interpolation map, b) NDVI calculation of the test site based on HyMap image.

the presence of substrates that had undergone significant chemical reactions resulting in different reflectance properties. In the south-eastern part of the quaternary sand a consistently minor negative difference between NSMI and field values can be identified in an area with low vegetation cover. This effect is likely due to an overestimation of the in-situ dataset caused by an increasing amount of relatively moist clay particles below the surface here.

Figure 10 shows pixelwise correlations between predicted soil moisture from remote sensing and estimated values from field data. Pixels representing the artificially wetted area as well as pixels showing artifacts at the substrate border were removed prior to the regression analysis. The linear regression function exhibits a high coefficient of determination $\left(\mathrm{R}^{2}=0.82\right)$, with an RMSE of $2.3 \%$. Sources of deviation are caused by several factors, but can be explained by uncertainties in the measurements and influencing covariates. 
The graph confirms the assumption that vegetation cover severely influences the NSMI accuracy as discussed above. Pixels with high NDVI values (mainly quaternary substrates) deviate from the 1:1-line. Between 5 and 20\%, NSMI values are generally higher than the in-situ estimates, as the data points in the diagram mainly occur below the 1:1-line. This results in a non-linearity visible in the scatter plot, which is mainly due to the vegetation cover in this range of values. For high NSMI estimations (with lower associated NDVI values) the discrepancy between the two estimations is increasingly replaced by a random deviation. However, the nonlinearity visible in the graph might also indicate a saturation of the NSMI for higher values, which corresponds with Ref. 18.

Figure 10 shows that for quaternary samples affected by iron compounds $\left(\mathrm{Fe}_{2} \mathrm{O}_{3}\right)$, the data points spread significantly within the range between 9 and $20 \%$, where NSMI values are in many cases smaller than in-situ estimates. This effect is likely to have two causes: an overestimation of the FDR device in the field due to different substrate compositions as well as specific soil properties at the surface that affect the NSMI value. Tertiary samples showing minor surface soil moisture values are clustered near the origin of the graph. Major deviations from the 1:1line exist only for a few pixels showing increased NDVI values.

Pixels covering quaternary substrates with inorganic crusts, which were observable in the field, tend to cluster below the 1:1-line at high soil moisture values. The role of these crusts has not further been analyzed in this study, but obviously they do affect NSMI model outcome to some degree. Studies on soil crusts confirm their implications on reflectance values [7, 8].

As can be seen from Fig. 10, a significant proportion of soil moisture values is scattered between 0 and 3\%. While these values are characteristic for the test site, they also tend to artificially improve the coefficient of determination. An additional sub-dataset has therefore been generated consisting of $n=808$ observations, in which $75 \%$ of the measurements with NSMI-based values below $3 \%$ have been eliminated (regular sampling). As a consequence, the data points scatter more evenly in the range of values, while RMSE increases from 2.3 to $2.7 \%$ and can still be seen as acceptable.

In summary, a good conformance on a pixel-by-pixel basis can be observed between the remote sensing based NSMI and in-situ datasets. Spatial surface soil moisture patterns in the field are reproduced and gradients within each substrate as well as sharp transitions between substrates show up in both datasets. However, the given results have to be interpreted against the background of the different sources of uncertainties. With respect to the error margin, absolute values in the heterogeneous parts of the quaternary sand need to be interpreted with care.

Comparing the outcome of the applied NSMI model with normalized difference models using adjacent HyMap bands, the coefficient of determination has been calculated for each modified quantifier and can be seen in Table 4.

The comparison confirms that the selected HyMap bands provided best results in this study. However, using adjacent bands would decrease the coefficient of determination only marginally. Corresponding with the results from Ref. 18, the wavelengths chosen for the NSMI are representing a local maximum for soil moisture quantifications within a range of similarly effective bands for the NSMI. The decline in $\mathrm{R}^{2}$ is small near the chosen bands before increasing with distance in the spectrum.

Regarding the outcomes of Ref. [17] and previous works, these results can be explained by the typical effects in the SWIR. The overall decrease in reflectance with increasing soil moisture has been quantified in the Soil Moisture Gaussian Model by analyzing the convex hull of the log-spectrum over corresponding wavelengths. The NSMI channels at 1800 and $2119 \mathrm{~nm}$ represent local reflectance maxima and as such form anchor points in the convex hull. Thus, the two channels combined as a normalized difference represent a simplified quantifier relying on the same effect as the SMGM quantification. 


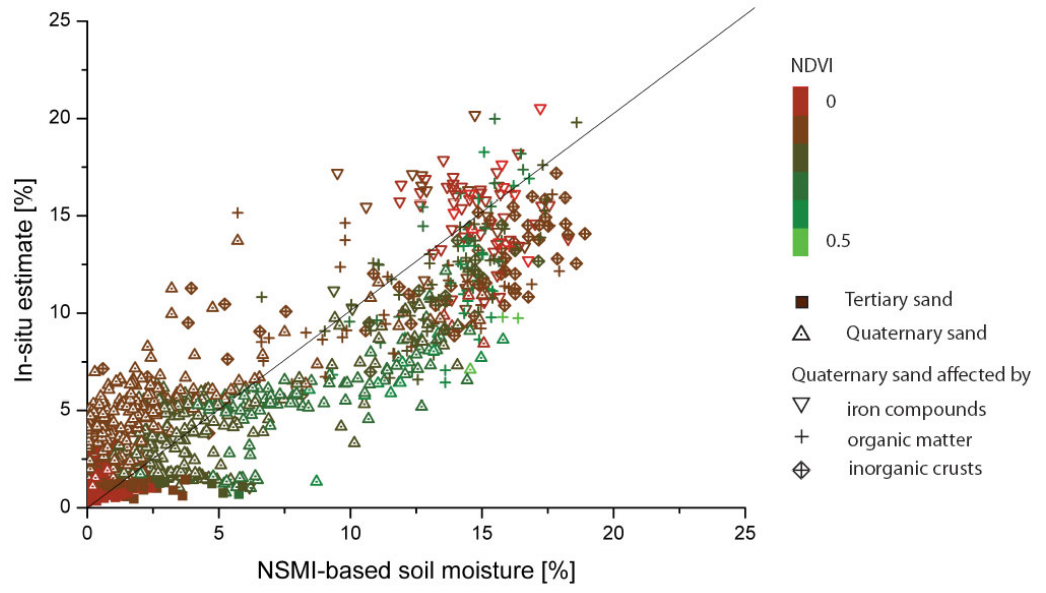

Fig. 10. Pixelwise correlation between in-situ soil moisture estimates and HyMap-based NSMI quantification (RMSE $=2.3 \%$; $\mathrm{n}=1806$ ). NSMI pixel values biased by watering were removed beforehand. The 1:1-line represents equal values. Substrates are differentiated by symbology, the color represents the NDVI value of the pixel.

Table 4. $\mathrm{R}^{2}$-values of normalized difference quantifications with adjacent HyMap bands. For each model outcome a linear regression with the same generated in-situ dataset has been quantified. Wavelengths are shown as from the HyMap calibration in 2005.

\begin{tabular}{|c|c|c|}
\hline Band 1 & Band 2 & $\mathrm{R}^{2}$ \\
\hline НyМар 93 (1798nm)* & НyМар 100 (2048nm) & 0.813 \\
\hline НyМар $93(1798 \mathrm{~nm})^{*}$ & НуМар 101 (2066nm) & 0.816 \\
\hline НyМар $93(1798 \mathrm{~nm})^{*}$ & НуМар 102 (2084nm) & 0.816 \\
\hline НyМар $93(1798 \mathrm{~nm})^{*}$ & HyMap 103 (2102nm) & 0.817 \\
\hline HyMap 93 (1798nm)* & HyMap 104 (2120nm) & 0.819 \\
\hline HyMap $93(1798 \mathrm{~nm})^{*}$ & HyMap 105 (2138nm) & 0.819 \\
\hline HyMap $93(1798 \mathrm{~nm})^{*}$ & НyMap 106 (2156nm) & 0.807 \\
\hline HyMap $93(1798 \mathrm{~nm})^{*}$ & HyMap 107 (2173nm) & 0.797 \\
\hline HyMap $93(1798 \mathrm{~nm})^{*}$ & HyMap 108 (2190nm) & 0.781 \\
\hline НyМар 89 (1750nm) & НуМар 104 (2120nm)* & 0.808 \\
\hline НyМар 90 (1762nm) & НyMap $104(2120 \mathrm{~nm})^{*}$ & 0.810 \\
\hline НyМар 91 (1774nm) & НyMар $104(2120 \mathrm{~nm})^{*}$ & 0.813 \\
\hline HyMap 92 (1786nm) & НyМар $104(2120 \mathrm{~nm})^{*}$ & 0.818 \\
\hline HyMap 93 (1798nm) & НуМар $104(2120 \mathrm{~nm})^{*}$ & 0.819 \\
\hline НyМар 94 (1810nm) & НуМар 104 (2120nm)* & 0.799 \\
\hline
\end{tabular}


Since reflectance values above $2119 \mathrm{~nm}$ are increasingly affected by clay minerals like smectite and kaolinite in the given substrates, regression outputs fall off in this direction. On the other side, reflectance values are getting influenced by atmospheric noise towards the major water absorption band at $1900 \mathrm{~nm}$, and regression coefficients decrease accordingly when corresponding channels are chosen for the generation of a normalized difference index.

Since vegetation (especially dry vegetation) was sparse in the test site of this study, the influence of cellulose and lignin on reflectance around 2100nm could be neglected here [35]. The Cellulose Absorption Index (CAI) is based on an absorption band at $2106 \mathrm{~nm}$, which is compared to cellulose-invariant reflectance values at 2015 and $2195 \mathrm{~nm}$. It might therefore be necessary to shift the chosen channels slightly in the case that crop residues or other types of organic matter affect the second band used in the NSMI calculation.

\subsection{Multi-temporal NSMI analysis}

A multi-temporal soil moisture analysis based on the NSMI model has been performed to show the potential of monitoring soil moisture from airborne sensors covering the hydrological mesoscale. Figure 11 shows the results of applying the above calibrated NSMI model to the HyMap datasets from July 2004. Figures 11 a and 11 b both clearly show a typical spatial surface soil moisture distribution over the test site, which is similar to the distribution of soil moisture in June 2005. The image from late July 2004 (11 b) indicates relatively high soil moisture values over the whole area. A difference image (Fig. $11 \mathrm{c}$ ) shows an overall increase in soil moisture content within the 26 days (blue values). The actual increase rate forms a very distinct pattern. First it can be noted that surface soil moisture differences are much stronger in the quaternary substrate. This corresponds with the fact that the substrate generally exhibits higher soil moisture values $[18,28]$. Due to its physical properties it is able to store water longer than the tertiary sand. Also within this substrate differences in soil moisture increase can be observed: the highest values are located in the transition zone between the tertiary and quaternary substrates. This area is characterized by the accumulation of water that previously discharged from the tertiary part further north. The NSMI approach reflects these exceptionally high GSM values in the map. Additionally, in areas of relatively high vegetation cover, the NSMI increases significantly as well, which is also the consequence of increased plant growth due to higher soil water availability. Precipitation data as well as field soil moisture are shown in Fig. $11 \mathrm{~d}$ and e for June and July 2004. The higher soil moisture values in the later HyMap scene fit well with precipitation and moisture measurements in the field: the higher values indicated by Fig. $11 \mathrm{e}$ in the end of July are coherent with both, the much higher precipitation amounts in the second half of July and the in-situ soil moisture measured by the echo probe.

\subsection{Assessment of the NSMI method}

Most approaches focusing on soil moisture quantification from reflectance data are either based on laboratory measurements or have not been validated thoroughly in the field by surface soil moisture in-situ measurements on a pixel-by-pixel basis. In this study a small catchment of 4ha size allowed for accurate geometrical and spectral analyses and especially for providing a comprehensive set of validation points in the field.

The correlation accuracies achieved are below the values from other studies $[15,17]$ performed in the laboratory. However, the natural environment in the field has not caused the NSMI approach to fail here. Instead, strengths were found in quantifying wide ranges of soil moisture and in detecting spatial patterns. The NSMI allowed on the one hand for the detection of relative changes within as well as between substrates with different spectral properties. Quantification deviations with respect to the FDR-based map have been -0.3\% GSM in average. Limitations of the NSMI are linked to the presence of vegetation (single deviation values can be 


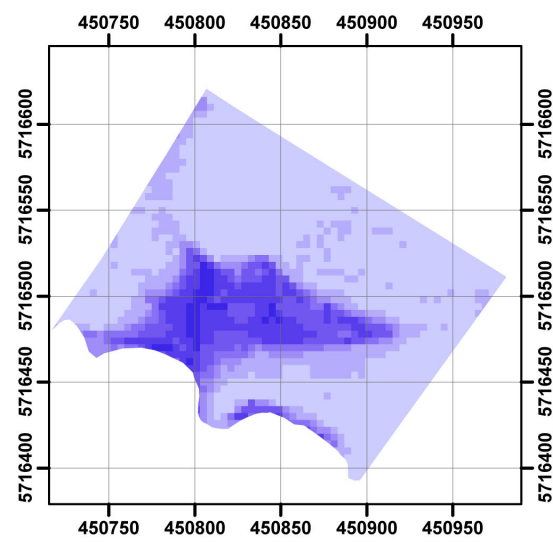

a) 2004, July 4th

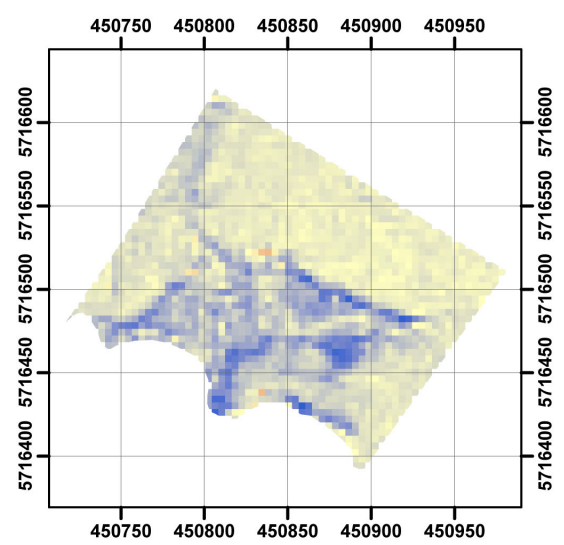

c) Difference (b - a)

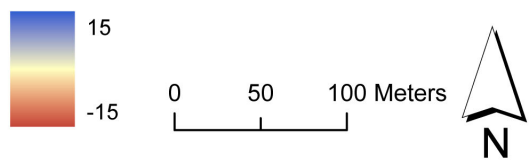

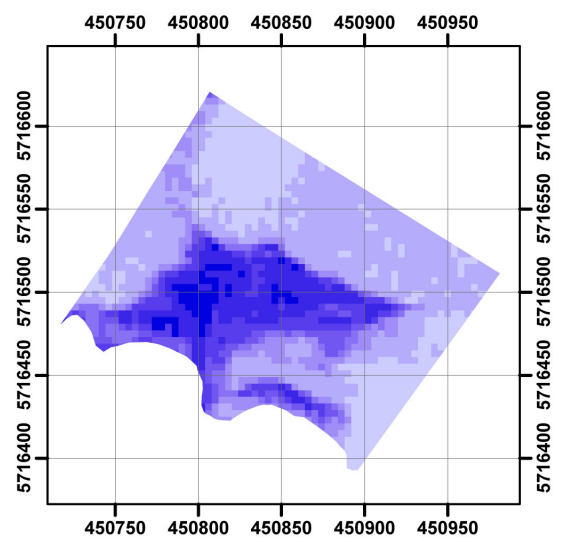

b) 2004, July 30 th
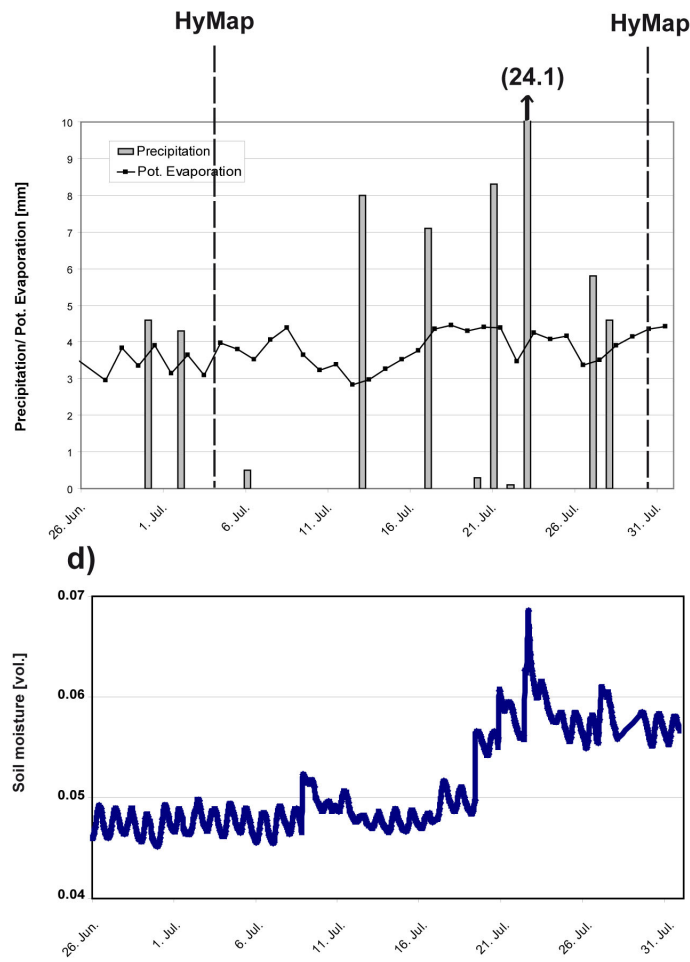

e)

Fig. 11. Soil moisture determination from HyMap 2004 images based on NSMI model for a) scene from July 4th, b) scene from July 30th. c) Difference in soil moisture estimation (b-a), d) meteorological variables in June and July 2004, e) soil moisture measured by echo probe at a single reference point (tertiary sand). 
up to $13 \%$ GSM for NDVI > 0.3). However, these restrictions also apply for most other studies and models.

The hyperspectral sensor used in this study provides very high spectral resolution images, which allowed to determine NSMI from narrow-band sensors and to analyze spectral differences in the area. The minor shift of the two used HyMap bands compared to the NSMI bands used for laboratory spectra did not affect the performance of the quantification here. The transferability of the NSMI to broadband sensors holds promises, but has yet to be confirmed.

\subsection{Assessment of the validation approach}

This paper presents the production of a pixel-by-pixel validation soil moisture map generated on the basis of real-time in-situ field measurements. Soil moisture pixel-by-pixel maps derived on the basis of FDR measurements and subsequent processing steps are independent validation datasets that reflect an optimum trade-off between sample number and timeliness at this scale. Such a study has not been published so far, as validation is often produced with a relatively small number of field measurements at real-time. When higher numbers of field samples could be collected in other studies, they were mostly either not taken at overflight time or were analyzed in the laboratory hours or days after collection, since it is unfeasible to directly collect a sufficient number of surface soil moisture values in the short time frame associated with a remote sensing acquisition. In the approach presented here, the collection of a high number of soil moisture values was possible due to the combination of the quick measurement process of the FDR device and an additional smaller number of soil core samples, allowing for the generation of a dense mesh of validation data. The interpolation of these point measurements further improved correlation in a validation subset, since spatial variability caused by local inconsistencies has been smoothed by adjacent pixel values.

The approach followed here to generate the in-situ dataset is subject to a number of uncertainties and can only be applied when certain preconditions are met. The interpolation itself is only valid when the density of base points is high enough, which proved to be the case for most but not all parts of the study area. Additionally, spatial interpolation can be critical at this scale when no sharp boundaries between different substrates exist, since continuous transition zones cannot be taken into account appropriately. However, this source of error becomes less significant with an increasing size of the area covered. The deduction of gravimetric soil moisture values based on the volumetric values taken with the FDR device had to be simplified, since an average bulk density value was used here for the whole area. This is only valid in the case that substrates do not differ significantly in their physical properties. One critical assumption that had to be made when using FDR devices is related to the vertical soil moisture distribution. Since surface values are of interest and in fact average values over the upper five centimeters are measured, a correction factor had to be implemented based on substrate-typical patterns. Applying this factor postulates that vertical soil moisture profiles are relatively homogeneous and well-known, which is only the case in certain phases of the drying process after precipitation events [9].

Considering all uncertainties and inaccuracies that are associated with field data and with the methodology developed here for in-situ map generation, an optimum validation data set combining information of spatial coverage and vertical soil moisture profile has been generated, allowing to determine an RMSE based on pixelwise comparisons between remote sensing estimation and field validation.

\section{CONCLUSIONS}

The studies described in this paper involve the first application of the recently established surface soil moisture quantification approach NSMI to a hyperspectral airborne sensor. The following main results can be concluded. 
- The NSMI has been applied successfully as an easy-to use, comprehensible model for surface soil moisture quantification in an area of quaternary and tertiary sands with absent to low vegetation cover. The high spectral resolution of the HyMap sensor made a quantification based on two bands in the SWIR possible.

- The strength of the NSMI in this study is particularly in detecting soil moisture variations over a wide range of values in sandy substrates. Naturally occurring soil moisture gradients within a substrate are detected by the NSMI. Additionally, a larger range of soil moisture values has been reproduced by the quantification model in an artificially wetted area. The accuracy of the NSMI is consistent within the range between 0 and 20\% GSM with an average RMSE of $2.3 \%$.

- Soil types affect the parameters of the regression function differently. Chemical composition and the presence of crusts need to be taken into account when calibrating the model for a specific area. Further research is therefore necessary to analyze the applicability of the NSMI in regions with other soil types.

- Vegetation density exceeding a certain threshold value leads to overestimation. The maximum threshold value for which the NSMI still delivers valid results was observed to be at 0.3 in our test site. For an application of the NSMI in agricultural areas, further analyses concerning the effect of crop residues are of specific interest.

- The validation of remote sensing estimates with in-situ soil moisture is afflicted with different types of uncertainties. Substrate information on vertical soil moisture profiles of proxy samples proved to be feasible for calibrating FDR measurements with an overall RMSE in the validation dataset of $1.94 \%$. FDR-based point measurements density was adequate for the homogeneous tertiary substrate, but need a higher spatial resolution in environments with heterogeneous surface properties in order to be usable for validation purposes. With the interpolation method applied here (RMSE 2.07\%), an overall appropriate in-situ validation dataset could be generated.

- While the HyMap bands chosen for the NSMI calculation provided best results in this study, the use of adjacent wavelengths turned out to result in only marginally lower coefficients of determination. The chosen NSMI bands can therefore be seen as representing a locally optimum choice for soil moisture quantification, while they may be substituted by adjacent or broader bands if necessary. As a consequence, applying the NSMI to other sensor types might be feasible, but yet needs to be analyzed in detail.

This study is a new attempt to link remote sensing prediction with hydrological in-situ measurements. It shows that a gap has to be filled between two research domains - optical remote sensing science that focuses on the uppermost part of the surface, and the hydrological research community studying processes within and between different soil layers. Especially in areas with low vegetation cover, rainfall events yield in runoff coefficients that are heavily depending on the antecedent soil moisture [36]. Besides major challenges in fully understanding soil surface processes, optical data could make an indispensable contribution to describe the vertical profile of soil water content and also serves as a spatial index of the soil surface hydraulic properties [9]. The use of reflectance measurements to quantify surface soil moisture is therefore invaluable for hydrological modeling approaches.

Soil erosion models covering areas at the mesoscale $\left(10^{1}\right.$ to $\left.10^{3} \mathrm{~km}^{2}\right)$ are of specific interest for hydrologists [1]. Spaceborne hyperspectral sensors with their high spatial coverage and temporal resolution will allow for quickly generating datasets on surface soil moisture in the future based on methods such as the one presented in this paper. Consequently, datasets from remote regions will be available, making a significant contribution to monitor and improve the 
understanding of surface and near-to-surface soil processes, where surface soil moisture is a key variable.

\section{Acknowledgments}

This research has been conducted within the project "Quantification of near-surface processes in the context of land degradation for the characterization of soil properties, erosion and water regime", funded by GFZ German Research Centre for Geosciences. It is a joint project between the GFZ and the Brandenburgische Technische Universität (BTU) Cottbus, part of the GFZ program "Climate Variability and Human Habitat, Monitoring of Climate-Sensitive Regions". The authors especially thank Christine Lemmnitz from BTU Cottbus for her work and assistance in field and laboratory. For their assistance in the field we would also like to thank Jan Anderssohn, Mathias Bochow, Nicole Richter, Daniel Spengler, Katrin Zabel and Ute Zaplinski. Further, we wish to thank the HyEurope team at the German Aerospace Center (DLR) for data acquisition and support during the field campaigns.

\section{References}

[1] W. Merritt, R. Letcher, and A. Jakeman, "A review of erosion and sediment transport models," Environ. Model. Software 18, 761-799 (2003). [doi: 0.1016/S1364-8152(03)00078$1]$.

[2] R. Watson, R. Moss, and M. Zinyower, The Regional Impacts of Climate Change: An Assessment of Vulnerability, IPCC Special Report, Cambridge University (1998). [doi: 10.2277/0521634555].

[3] A. Porporato, E. Daly, and I. Rodriguez-Iturbe, "Soil water balance and ecosystem response to climate change," Am. Nat. 164(5), 625-632 (2004). [doi: 10.1086/424970].

[4] A. K. Knapp, P. Fay, J. Blair, S. Collins, M. Smith, J. Carlisle, C. Harper, B. Danner, M. Lett, and J. McCarron, "Rainfall variability, carbon cycling, and plant species diversity in a mesic grassland," Science 298, 2202-2205 (2002). [doi: 10.1126/science.1076347].

[5] E. Ben-Dor and A. Banin, "Visible and near-infrared (0.4-1.1 $\mu \mathrm{m})$ analysis of arid and semiarid soils," Rem. Sens. Environ. 48, 261-274 (1994).

[6] M. Baumgardner, "Reflectance properties of soils," Adv. Agron. 38, 1-44 (1985).

[7] N. Goldshleger, E. Ben-Dor, Y. Benyamini, D. Blumberg, and M. Agassi, "Spectral properties and hydraulic conductance of soil crusts formed by raindrop impact," Int. J. Rem. Sens. 23(19), 3909-3920 (2002). [doi: 10.1080/01431160110115942].

[8] N. Goldshleger, E. Ben-Dor, Y. Benyamini, and M. Agassi, "Soil reflectance as a tool for assessing physical crust arrangement of four typical soils in Israel," Soil Sci. 169, 677-687 (2004).

[9] W. Capehart and T. Carlson, "Decoupling of surface and near-surface soil water content: a remote sensing perspective," Water Resour. Res. 33(6), 1383-1395 (1997).

[10] K. Huemmrich, "The GeoSail model: a simple addition to the SAIL model to describe discontinuous canopy reflectance," Rem. Sens. Environ. 75, 423-431 (2001). [doi: 10.1016/S0034-4257(00)00184-X].

[11] W. Verhoef and H. Bach, "Coupled soil-leaf-canopy and atmosphere radiative transfer modeling to simulate hyperspectral multi-angular surface reflectance and TOA radiance data," Rem. Sens. Environ. 109, 166-182 (2007). [doi: 10.1016/j.rse.2006.12.013].

[12] H. Bach and W. Verhoef, "Sensitivity studies on the effect of surface soil moisture on canopy reflectance using the radiative transfer model GeoSAIL," in IEEE 2003 International Geoscience and Remote Sensing Symposium Proceedings, 3, 1679-1681 (2003).

[13] W. Planet, "Some comments on reflectance measurements of wet soils," Rem. Sens. Environ. 1, 127-129 (1970). [doi: 10.1016/S0034-4257(70)80014-1]. 
[14] D. Lobell and G. Asner, "Moisture effects on soil reflectance," Soil Sci. Soc. Am. J. 66, 722-727 (2002).

[15] L. Weidong, F. Baret, G. Xingfa, T. Qingxi, Z. Lanfen, and Z. Bing, "Relating soil surface moisture to reflectance," Rem. Sens. Environ. 81, 238-246 (2002). [doi: 10.1016/S00344257(01)00347-9].

[16] L. Weidong, F. Baret, G. Xingfa, Z. Bing, T. Qingxi, and Z. Lanfen, "Evaluation of methods for surface soil moisture estimation from reflectance data," Int. J. Rem. Sens. 24(10), 2069-2083 (2003). [doi: 10.1080/01431160210163155].

[17] M. Whiting, L. Li, and S. Ustin, "Predicting water content using Gaussian model on soil spectra," Rem. Sens. Environ. 89, 535-552 (2004). [doi: 10.1016/j.rse.2003.11.009].

[18] S. Haubrock, S. Chabrillat, C. Lemmnitz, and H. Kaufmann, "Surface soil moisture quantification models from reflectance data under field conditions," Int. J. Rem. Sens. 29(1), 3-29 (2008). [doi: 10.1080/01431160701294695].

[19] G. Profeti and H. Macintosh, "Flood management through landsat TM and ERS SAR data: a case study," Hydrolog. Process. 11, 1397-1408 (1997). [doi: 10.1002/(SICI)10991085(199708)11:10<1397::AID-HYP530>3.0.CO;2-Y].

[20] S. Vincente-Serrano, X. Pons-Fernandez, and J. Cuadrat-Prats, "Mapping soil moisture in the central Ebro river valley (northeast Spain) with Landsat and NOAA satellite imagery: a comparison with meteorological data," Int. J. Rem. Sens. 25(20), 4325-4350 (2004). [doi: 10.1080/01431160410001712990].

[21] Y. Zhang and M. Wegehenkel, "Integration of MODIS data into a simple model for the spatial distributed simulation of soil water content and evapotranspiration," Rem. Sens. Environ. 104(4), 393-408 (2006). [doi: 10.1016/j.rse.2006.05.011].

[22] S. Khanna, A. Palacios-Orueta, M. Whiting, S. Ustin, D. Riano, and J. Litago, "Development of angle indexes for soil moisture estimation, dry matter detection and land-cover discrimination," Rem. Sens. Environ. 109(2), 154-165 (2007). [doi: 10.1016/j.rse.2006.12.018].

[23] E. Muller and H. Décamps, "Modeling soil moisture - reflectance," Rem. Sens. Environ. 76, 173-180 (2000). [doi: 10.1016/S0034-4257(00)00198-X].

[24] R. Bryant, D. Thoma, S. Moran, C. Holifield, D. Goodrich, T. Keefer, G. Paige, W. D., and S. Skirvin, "Evaluation of hyperspectral, infrared temperature and radar measurements for monitoring surface soil moisture," in 1st Interagency Conference on Research in the Watersheds, 528-533, (Benson, Arizona) (2003).

[25] I. Bogrekci and W. S. Lee, "The effects of soil moisture content on reflectance spectra of soils using UV-VIS-NIR spectroscopy," in 7th International Conference on Precision Agriculture, (Minneapolis) (2004).

[26] U. Wendling, G. Fuchs, and G. Müller-Westermeier, Mittlere jährliche Verdunstungshöhe als Gras-Referenzverdunstung, Hydrologischer Atlas von Deutschland 2.12, Bundesministerium für Umwelt (1999).

[27] I. W. G. WRB, "World reference base for soil resources," tech. rep., FAO (2006).

[28] C. Lemmnitz, M. Kuhnert, O. Bens, A. Güntner, B. Merz, and R. Hüttl, "Spatial and temporal variations of actual soil water repellency and their influence on surface runoff," Hydrolog. Process. 22, 1976-1984 (2008). [doi: 10.1002/hyp.6782].

[29] F. Wisotzky and P. Obermann, "Acid mine groundwater in lignite overburden dumps and its prevention - the rhineland lignite mining area (Germany)," Ecol. Eng. 17(2-3), 115-123 (2001). [doi: 10.1016/S0925-8574(00)00152-X].

[30] T. Cocks, R. Jenssen, A. Stewart, I. Wilson, and T. Shields, "The hyMap airborne hyperspectral sensor: The system, calibration and performance," in 1st EARSeL Workshop on Imaging Spectroscopy, (Zurich) (1998). 
[31] A. Nadler, S. Dasberg, and I. Lapid, "Time domain reflectometry measurements of water content and electrical conductivity of layered soil columns," Soil Sci. Soc. Am. J. 55, 938 943 (1991).

[32] T. Heimovaara, "Frequency domain analysis of the time domain reflectometry waveforms - measurement of the complex dielectric permittivity of soils," Water Resour. Res. 30(20), 189-199 (1994).

[33] A. Berk, G. P. Anderson, P. Acharya, M. L. Hoke, J. H. Chetwynd, L. S. Bernstein, E. P. Shettle, M. W. Matthew, and S. M. Adler-Golden, "MODTRAN 4 version 3 revision 1 User's Manual," tech. rep., Air Force Research Laboratory (2003).

[34] D. Shepard, "A two-dimensional interpolation function for irregularly-spaced data," in 23rd National Conference ACM, 517-524, ACM (1968).

[35] C. Daughtry, E. Hunt Jr., and J. McMurtrey III, "Assessing crop residue cover using shortwave infrared reflectance," Rem. Sens. Environ. 90, 126-134 (2004). [doi: 10.1016/j.rse.2003.10.023].

[36] K. Beven, "Runoff generation in semi-arid areas," in Dryland Rivers: Hydrology and Geomorphology of Semi-Arid Channels, L. Bull and M. Kirkby, Eds., 57-105, Wiley \& Sons, Chichester (2002). 